Proceedings of the Seminar on the Social and Economic Effects

of Earthquake Prediction, 12 October, 1977.

\title{
CIVIL DEFENCE ASPECTS
}

\author{
R. H. F. Holloway*
}

\section{INTRODUCTION}

In New Zealand, Civl Defence exists because many natural hazards and man-made accidents can create disasters of dimensions that could not be dealt with by the normal emergency services. The destructive earthquake without warning is probably the most difficult and dangerous threat to public safety for Civil. Defence to contend with. Most other causes of disaster either have some degree of warning or are relatively localised compared with the sudden and widespread effects of a major earthquake. Civil Defence planning is, in a sense, already based upon a vague and imprecise prediction of earthquakes known to be more likely to occur in some areas than in others and accepted as likely to happen at any time. The effect on Civil Defence of better earthquake prediction will depend on the probability, accuracy (in time, location and magnitude) of such prediction and how soon before the event it can be made.

\section{CIVIL DEFENCE OPERATIONS}

Civil Defence is concerned with the safety and welfare of people. The preservation and restoration of property, buildings or other facilities vulnerable to destruction are the concern of Civil Defence only insofar as the safety of people is concerned. Civil Defence operations are based initially on community self help. Local authorities are expected in the first instance to deal with emergencies using the resources already in day-to-day use augmented by voluntary organisations, individual volunteers and where necessary the local resources of government departments. Each local authority has a legal obligation to set up a Civil Defence organisation or to unite with others in doing so and to maintain a workable Civil Defence plan. In every such plan a Civil Defence controller is nominated and during a state of Civil Defence emergency (which he has the authority to declare) he may exercise quite sweeping powers within his district. An emergency may require co-operation between neighbouring Civil Defence organisations and the introduction of resources from outside the disaster area. The control and co-ordination of Civil Defence operations beyond the capability of a local authority to accomplish without external assistance is the responsibility of the Ministry of Civil Defence which has established a National Operational Headquarters in Wellington and Regional Headquarters in Auckland, Palmerston North and Christchurch. The Director of Civil Defence and his three Regional Commissioners have a co-ordinating function not only over local authority Civil Defence organisations but in respect of all Government Departments contributing to Civil Defence planning and operations. No Civil Defence headquarters or organisations are fully manned ready to operate at all times. All depend upon the calling up of volunteers and the assumption of responsibilities only when it has been established that a disaster has already occurred. In a disaster that assumes national proportions direct control of Civil Defence operations through the National Headquarters may be taken over by a Cabinet Committee for Civil Defence authorised to act on behalf of Government. Where it becomes necessary to replace a local authority that either has ceased to exist or is incapable of handling an emergency situation a Commissioner for Disaster Recovery may be appointed with special powers.

\section{CIVIL DEFENCE PLANNING}

Although the co-ordination and execution of Civil Defence measures rests with the Director of Civil Defence, a National Civil Defence Committee has the responsibility to review and report on Civil Defence planning and measures. This committee which consists of the Permanent Heads of thirteen Departments of State (and the Director of Civil Defence) oversees the plans produced by a number of independent Civil Defence national planning committees appointed by the Minister of Civil Defence. Each national planning committee is allotted a specific aspect of Civil Defence such as communications, medical, transport, welfare and evacuation, etc. and its members are drawn from Departments of State, other Government agencies, statutory corporations and associations of local authorities or public bodies which have a general responsibility for carrying out the functions associated with the specific aspect of Civil Defence. It is implicit that Civil Defence is not a responsibility of a single Department of state but is a shared responsibility amongst all Departments allotted a function in a national plan approved by the Minister of Civil Defence.

Civil Defence planning at national level is not related to particular threats or specific areas but deals in the main with the principles to be followed and the organisational preparations that should be made to meet any emergency situation. At local level some planning against recognisable threats to the particular district may be reflected in the local Civil Defence plan but again planning is chiefly organisational.

\section{PREDICTED EARTHQUAKE EFFECTS}

Although the time, place and magnitude 
of an earthquake may be predicted, the effects may not be wholly predictable. Threats to human life in an earthquake are often at the end of a chain of events that only begins with the earth tremor. For example fire in built up areas has been shown to be one of the most serious threats to life following from an earthquake. Disease that may follow a ruptured sewerage system is a threat to Iife that may begin with an earthquake. Short of evacuating all people from the predicted location of a severe earthquake, and that is a course that is hardly feasible for any city or town, there are no precautions that can be taken that will rule out the need for the life saving and welfare operations. Every Civil Defence exercise based on an earthquake, is in some degree an attempt to predict the effects of that earthquake. Given that the effects deduced might constitute a prediction it is possible to assess what precautions might be taken. On 20 september the Ministry of Civil Defence conducted an exercise (called CIVDEX 6) to examine the decisions that would need to be taken by Government and its principal advisers following a major disaster. The setting portrayed an initial earthquake shock of magnitude 7.5 on the Richter scale centred one mile east of the city of Nelson on the morning of 20 septenber. The preparation of the exercise began several months before with several Government Departments estimating the effects of the earthquake and its aftershocks from isoseismal maps prepared by the Seismological observatory. Where data was required of resources needed to deal with the disaster the actual situation on the morning of 21 June was assumed to be that when the initial earthquake shock struck. The estimate of effects were translated into the information which could reasonably be expected to have been reported day by day. On this basis the exercise participants examined the decisions that would need to be taken as the situation developed over a period of seven days. To the extent that the estimates of effects and possible restorative action can be accepted as accurate it is possible to determine the sort of things that might have been done had the exercise "earthquake" been predicted some months beforehand.

Although this earthquake was assessed to have caused damage and possibly casualties from Manawatu to North Canterbury, the areas of major disaster were Nelson/Motueka, Marlborough and the Wellington/Hutt Valley area. of these Nelson presented the most serious problems for relief operations. Assuming that no precautions were taken, the predicted effects in the Nelson area were as follows:-

(a) No significant evacuation or relief measures would be possible in the five days following the initial earthquake shock. Nelson would be isolated from access by road, sea and air except for small boats and helicopters. (The sea bed in the approaches to the port might have been uplifted and no vessels of any significant size could be risked until a hydrographic survey was carried out. The airport would be severely damaged.)

(b) Many would be killed in the city area and hundreds severely injured. The hospitals would be severely damaged and patients would need to be evacuated. (c) There would be no electric power, gas or safe water supply in the first week or until outside help could be brought in. The sewerage system would be badiy damaged and might be the cause of a major health hazard.

(d) Most city buildings would be badly damaged or destroyed. Much destruction would be caused by uncontrolled fires in built up areas. Thousands might be rendered homeless.

(e) Initially roads in the city area would be impassable to vehicular traffic. Bridges would be destroyed or rendered unsafe.

(f) For the first twenty-four hours there would be no communications with Nelson except for a post office emergency radio and through amateur radio operators.

(g) There would be no radio broadcast transmission from Nelson for the first thirty-six hours.

(h) The Civil Defence organisation and emergency services for the first forty-eight hours would at best be only partially effective.

Such a prediction, if accepted as probable, would lead to a decision that one way or another as many people as possible should be induced to leave the city area of Nelson before the earthquake struck.

Certainly all hospitals and other establishments for people in need of care and attention should be evacuated. Given time it should be possible to take precautions for emergency water supply, power, fire fighting and communications; to remove or demolish hazards; and to stockpile supplies and fuel. It might even be feasible to ensure access by road, sea and air following the earthquake. The pre-disaster planning and precautions and their social and economic consequences would obviously be matters of grave concern and consideration by Government. Government control and Government resources would be needed from the outset. The precautions that could be taken would reduce but not remove the threat to human life. There would be the same need for local Civil Defence organisations with their knowledge of the people and the local environment to operate in the post-disaster phase probably in corjunction with a Commissioner for Disaster Recovery co-ordinating with support from government resources. It would of course be necessary to activate local Civil Defence organisations before the event and take steps to ensure that the initial earthquake shock did not prevent their operation.

(NOTE: It should not be assumed that Nelson is especially vulnerable to a destructive earthquake or that the effects are more devastating here than they would be elsewhere. Nelson was chosen simply to provide some specifics.)

\section{CONCLUSION}

It is assumed that not all earthquakes would be predictable and many that are. 
would not be of sufficient force or in such locations as to constitute the serious threat to public safety portrayed in the example given. In any event there will be other causes of disaster with or without warning. The possibility that some earthquakes may be predicted does not invalidate the present concept of Civil Defence as an effective and economic means at the local level for dealing with emergencies. At national level the co-ordinating and planning responsibilities of the Ministry of Civil Defence and the twelve other government departments represented in the National Civil Defence Committee would need adaptation for dealing with the prediction of a major earthquake but not fundamental changes.

\section{DISCUSSION}

Dr. Adams asked about the length of warning which would be useful to Civil Defence. General Holloway thought a period of 3 to 4 months would be sufficient and that even if a longer warning period was given it is doubtful whether Civil Defence would need to respond until that time. He added that if an earthquake was predicted to occur at anytime within (say) the next 5 years, this would not change the situation.

Professor Vignaux thought that more could be done in the medium term. For example, earthmoving machinery or troops could be moved to the area. In repiy General Holloway said it was doubtful that medium or long term responses to a prediction were the responsibility of Civil Defence. He saw the role of Civil Defence as one of reinforcement of the local authority and of existing emergency services in an emergency.

Mr. Strachan commented that in a major disaster local Civil Defence personnel might have family priorities and that there might be advantages in using rescue teams from other regions. Mr. Eiby said that it is well known that people experiencing large earthquakes are subject to considerable initial shock and apathy. In the 1931 Napier earthquake a navy ship was anchored in the stream and therefore missed the main impact of the earthquake. The significant contribution of the navy in the relief operation was well documented. He cautioned against moving relief teams into the area before the earthquake.

General Holloway acknowledged that the local emergency service personnel might be affected by the disaster but he said that it had been shown time and again in small scale disasters that the self-help principle is much preferred to importing outside help. 